\title{
Removal of selected pesticides by adsorption
}

\author{
Mária Valičkováa ${ }^{a} J_{a}$ Derco $^{a}$, Katarína Šimovičováb \\ ${ }^{a}$ Faculty of Chemical and Food Technology, Slovak University of Technology, \\ Radlinského 9, 81237 Bratislava, Slovakia \\ ${ }^{b}$ Water Research Institute, Nábrežie L. Svobodu 5, 81249 Bratislava \\ maria.valickova@stuba.sk
}

\begin{abstract}
The paper is focused on the removal of selected priority hazardous substances. Five chlorinated pesticides, i.e. hexachlorobenzene (HCHB), hexachlorobutadiene (HCHBD), lindane (LIN), pentachlorobenzene (PCHB) and heptachlor ( $\mathrm{HCH})$ were selected as model pollutants. Higher volatility is characteristic for these substances. Adsorption of these pollutants on granular activated carbon (GAC), zeolite (Zeo) and activated sludge (AS) was investigated. The effect of contact time on the removal efficiency of studied substances was investigated. From results of the work it follows that the highest removal efficiency of studied substances was achieved by the adsorption on activated sludge. This was followed by adsorption efficiency on zeolite. The lowest removal efficiency was measured for adsorption on granular activated carbon.
\end{abstract}

Keywords: activated sludge, adsorption, granular activated carbon, zeolite

\section{Introduction}

Chemical pollution of surface water presents a threat to the aquatic environment. It effects chronic toxicity to aquatic organisms. It accumulates in the ecosystem, which results in the loss of habitats and biodiversity, as well as a threat to human health. Serious concern is represented by the group of chemicals and compounds known as priority substances (2000/60/EC). These substances are not degradable, but persist in the environment and accumulate in animal and plant tissues and thereby threaten human health and ecosystems. These substances include also some pesticides. They are biologically active and are used as trade resources, especially in agriculture. Pesticides enter the aquatic environment by the primary processes such as washing and soil erosion. Given the high accumulation ability of these substances for various organisms in water it becomes extremely dangerous also when their concentration in the waters is low. By our accession to the EU, we are committed to achieve by 2015 a good water status. In Annex 5 of Directive 2008/105/EC of 16 December 2008 on environmental quality standards in the field of water policy, there is a list of 33 priority substances (PS). The monitoring of surface waters in the EU countries is required. Our legislation (Government Regulation 269/2010) extends this list resulting in total of 59 substances. Among them are also pesticides hexachlorobenzene, hexachlorobutadiene, hexachlorocyclohexane (lindane) and pentachlorobenzene. These substances have long been applied in agriculture, forestry and aquatic ecosystems and they became important contaminants of groundwater and surface water. In addition, priority substances were also discharged to the aquatic ecosystem as waste products from industrial production. Over time, the content of these substances in the food chain increases and as a result increases the risks to people and ecosystems. It is therefore necessary to monitor and control the emission also of very small quantities of these substances. These substances show possible carcinogenic and mutagenic effects. High concentrations of herbicides were found in areas with extensive agricultural activity, while insecticides were found in urban streams (Kolpin et al., 1998, Gilliom et al., 1999). Agricultural activity is a major source of pesticide contamination for drinking water. Several treatment processes were examined to reduce concentrations of pesticides in water (Al Momani et al. 2004). Contamination of surface and groundwater in the range of $\mathrm{ng} / \mathrm{l}$ and $\mathrm{mg} / \mathrm{l}$ was confirmed (Felsot, 1996, Kolpin et al., 1998).

Adsorption on activated carbon is a very promising method for removing many micropollutants. For many substances, the steady-state concentrations were reached after several hours. Activated carbon is commonly used after biological step (Burns et al. 2010). This paper is focused on the study of adsorption of selected chlorinated substances on granular activated carbon (GAC), zeolite (Zeo) and activated sludge (AS), respectively.

\section{Materials and methods}

\section{Laboratory equipment}

Experiments were performed with model water which contained our chosen chlorinated pesticides, i.e. hexachlorobenzene, hexachlorobutadiene, pentachlorobenzene, lindane and heptachlor. Experiments were carried out in laboratory conditions. Granular activated carbon (GAC), zeolite and acti- 
vated sludge were used. $0.100 \mathrm{~g}$ of GAC and $1.00 \mathrm{~g}$ of zeolite with a particle size fractions $\mathrm{d}=0.315$ to $0.4 \mathrm{~mm}$ was applied. 0.135 liter of activated sludge with the concentration of $\mathrm{X}=3.068 \mathrm{~g} / \mathrm{l}$ was used for these adsorption experiments.

\section{Analytical methods}

Quantification of organochlorine pesticides in water was achieved by Gas chromatographic method after liquid-liquid extraction. n-Hexane 96 \%, p.a. for HPLC (Analytika, s.r.o.) was used as organic solvent. Extract was analyzed by gaschromatography with micro electron capture detector (Agilent Technologies 7890A GC Systems). All parent organochlorine compounds used for preparation of synthetic wastewater and standard stock solutions were purchased from Supelco Co in high quality.

\section{Results and discussion}

For the removal of pesticides from water, physical processes were used. The process of adsorption on granular activated carbon (GAC), on zeolite (Zeo) and sorption on activated sludge (AS) were investigated. As the wastewater is usually treated at biological stage of the wastewater treatment plant, we studied the extent of biosorption of these chlorinated substances on activated sludge (AS)m as well.

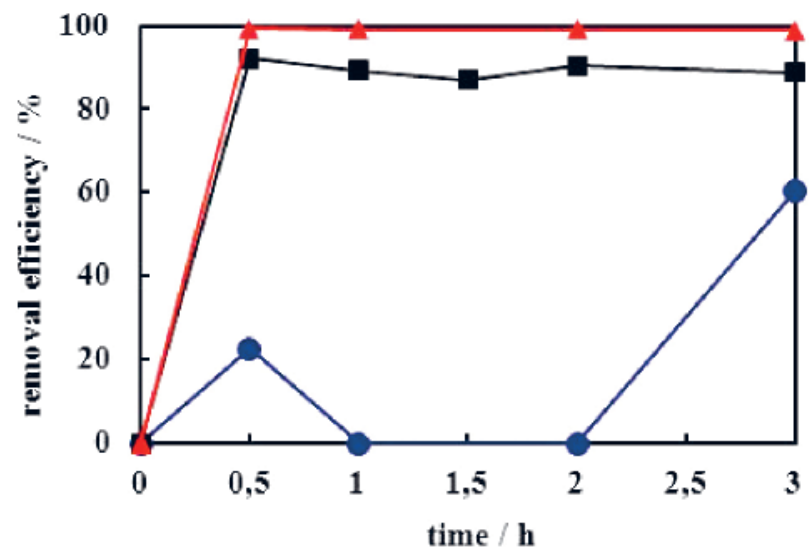

Fig. 1. Removal efficiency of heptachlor by the

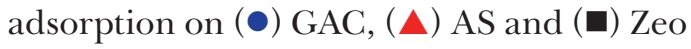
from model wastewater.

Fig. 1 shows the efficiency of removal of HCH during adsorption on GAC, Zeo and activated sludge (AS). The lowest removal efficiency is about $25 \%$ and it was achieved during the adsorption on GAC after $0.5 \mathrm{~h}$. The adsorption on Zeo reached about $95 \%$ removal efficiency at the same time. During the sorption on AS, the highest removal efficiency, almost $100 \%$, was achieved after $0.5 \mathrm{~h}$.

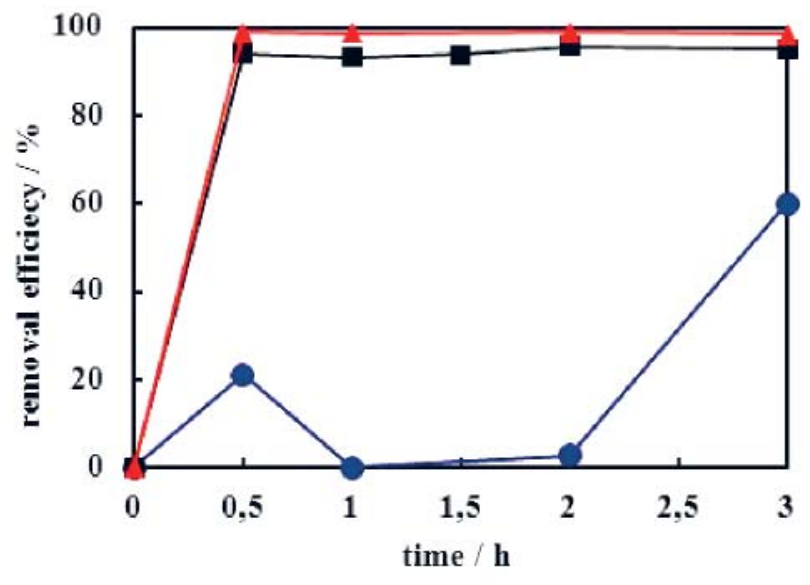

Fig. 2. Removal efficiency of hexachlorobenzene by the adsorption on $(\bullet) \mathrm{GAC},(\boldsymbol{\Delta}) \mathrm{AS}$ and $(\boldsymbol{\square})$ Zeo from model wastewater.

In Fig. 2, removal efficiencies achieved by the adsorption of $\mathrm{HCHB}$ on GAC, Zeo and AS are shown after 0.5 hours of adsorption time. Using GAC approximately $20 \%$ removal efficiency was achieved. With Zeo nearly $99 \%$ removal efficiency after $0.5 \mathrm{~h}$ adsorption has been reached. The highest treatment efficiency was achieved by the sorption on AS. In this case, almost $100 \%$ removal efficiency of HCHB was observed after $0.5 \mathrm{~h}$. No significant increase of treatment efficiencies was observed after prolongation of adsorption time up to 3 hours. The exception was GAC for which the adsorption removal efficiency increased to $60 \%$.

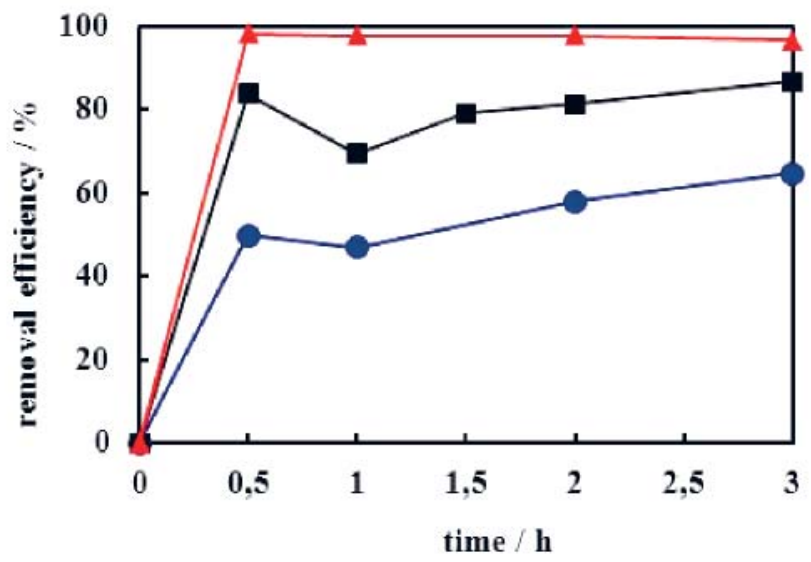

Fig. 3. Removal efficiency of hexachlorobutadiene

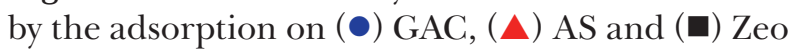
from model wastewater.

Fig. 3 illustrates the efficiencies of HCHBD removals for different adsorption materials. After $0.5 \mathrm{~h}$ of adsorption on GAC removal efficiency of about $50 \%$ was achieved. At the same time almost $85 \%$ removal efficiency was achieved by the adsorption on zeolite. The highest removal efficiency, approx. 
$99 \%$ of HCHBD, was measured for activated sludge.

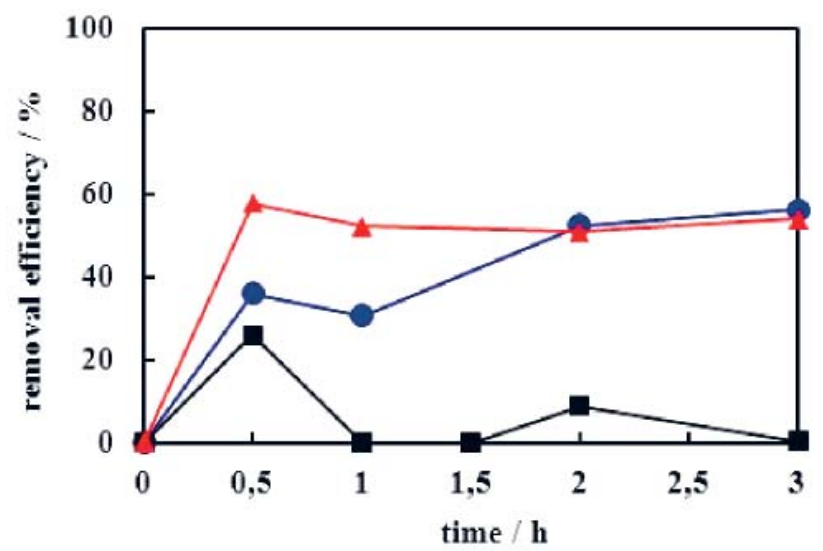

Fig. 4. Removal efficiency of lindane by the

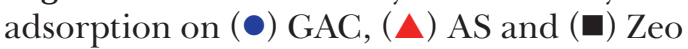
from model wastewater.

Time dependencies of LIN removal efficiencies are plotted in Fig. 4. For this substance, the adsorption on Zeo reached approximately $25 \%$ removal efficiency after $0.5 \mathrm{~h}$. About $35 \%$ removal efficiency of LIN was achieved using GAC for the same time. In the case of AS the highest removal efficiency of LIN, i.e. nearly $60 \%$, was observed.

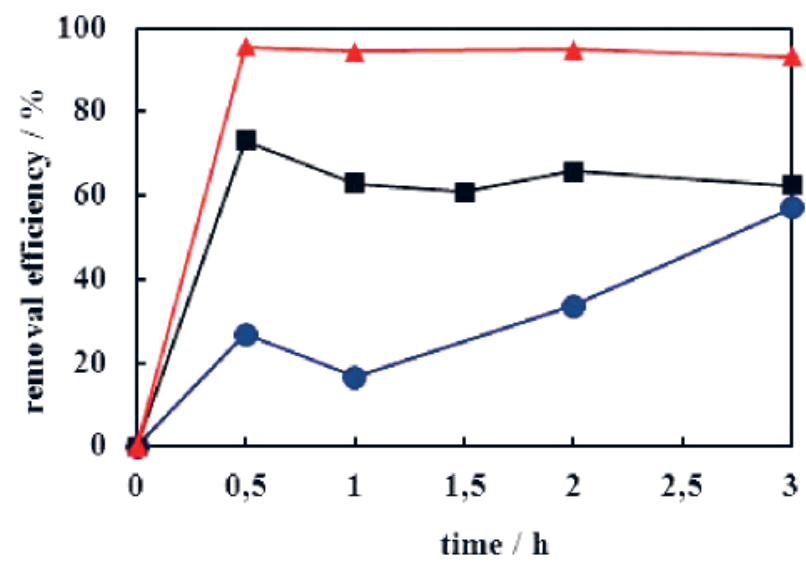

Fig. 5. Removal efficiency of pentachlorobenzene

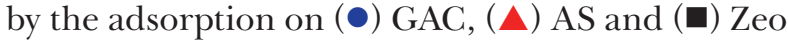
from model wastewater.

Fig. 5 shows time courses of PCHB removal efficiencies when applying the above mentioned adsorption materials. $30 \%$ removal efficiency was observed for GAC after $0.5 \mathrm{~h}$. Almost $75 \%$ removal efficiency was measured using Zeo. The highest removal efficiency (almost $99 \%$ ) of the substance was observed for AS. Likewise for HCHB, no significant changes in removal efficiencies were measured during longer time up to 3 hours with the exception of GAC (increase of removal efficiency to $60 \%$ ).

\section{Conclusion}

Removal of five selected priority substances by the adsorption on three different adsorbents was studied. The highest removal efficiencies were observed by the sorption on activated sludge. Maximum removal efficiencies observed during contact time $0.5 \mathrm{~h}$ were as follows:

$99.1 \%$ for $\mathrm{HCH}, 98.8 \%$ for HCHB, $98.1 \%$ for HCHBD, $95.3 \%$ for PCHB, and $57.6 \%$, for LIN. In the case of zeolite, maximum removal efficiency of $93.8 \%$ was measured after adsorption time $0.5 \mathrm{~h}$ for HCHB. The next highest efficiency, viz. $92.1 \%$ was achieved for $\mathrm{HCH}$, followed by HCHBD with removal efficiency of $83.7 \%$, PCHB with $72.9 \%$ removal efficiency and LIN with $25.8 \%$ removal efficiency.

Significantly higher adsorption time was required for activated carbon. However, using this adsorbent, lower removal efficiencies were achieved: $64.5 \%$ removal efficiency of HCHBD, $60.5 \%$ for $\mathrm{HCH}, 59.9 \%$ for HCHB, $57.0 \%$ for PCHB and $56 \%$ for LIN were measured after 3 hours of the process.

No significant increase of treatment efficiencies was observed after prolongation of adsorption time up to 3 hours with the exception of $\mathrm{HCHB}$ removal of GAC (adsorption removal efficiency increased to $60 \%)$.

\section{Acknowledgements}

The authors wish to thank for the support from VEGA Grant 1/0734/12.

\section{References}

Al Momani FA, Gamal El-Din M, Smith DW, Bhandari A, Hutchinson SL (2004) Water environmental research 76 (6): $1775-1856$.

Directive 2000/60/EC of the European parliament and of the council of 23 October 2000 establishing a framework for Community action in the field of water policy.

Directive 2008/105/EC of the European parliament and of the council of 16 December 2008 on environmental quality standards in the field of water policy, amending and subsequently repealing council Directives 82/176/EEC, 83/513/EEC, 84/156/EEC, 84/491/EEC, 86/280/EEC and amending Directive 2000/60/EC of the European parliament and of the council.

Decree of the Government of the Slovak Republic No. 269/2010 from May 25, 2010 which determines the requirements for good quality of waters.

Burns D (2010) Elimination of organic micropolluants in wastewater treatment plants. IWA. http://www.iwawaterwiki.org/xwiki/bin/view/ Articles/Eliminationoforganicmicropolluantsinwaste watertreatmentplants. 
Felsot AS (1996). Journal of Environmental Science and Health - Part B: Pesticides, Food Contaminants, and Agricultural Wastes 31(3): 365-381.

Gilliom RJ, Barbash JE, Kolpin DW, Larson SJ (1999) Environmental science technology 33 (7): 164A169A.
Kolpin DW, Barbash JE, Gilliom RJ (1998) Environmental science technology 32 (5): 558-566. 